\title{
Hemodynamically unstable wide QRS complex tachycardia: a case report
}

\section{Mislav Puljević*, Vedran Velagić, Borka Pezo-Nikolić, Davor Puljević}

University of Zagreb School of Medicine, University Hospital Centre Zagreb, Zagreb, Croatia
RECEIVED:

July 27, 2015

ACCEPTED:

September 17, 2015

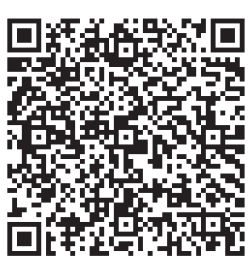

KEYWORDS: atrial fibrillation, wide QRS complex tachycardia.

CITATION: Cardiol Croat. 2015;10(9-10):230-231. | DOI: http://dx.doi.org/10.15836/ccar.2015.230

*ADDRESS FOR CORRESPONDENCE: Mislav Puljević, Klinički bolnički centar Zagreb, Kišpatićeva 12, HR-10000 Zagreb, Croatia. / Phone: +385-91-4680414 / E-mail: puljevicmislav@gmail.com

ORCID: Mislav Puljević, http://orcid.org/0000-0003-1477-2581 • Vedran Velagić, http://orcid.org/0000-0001-5425-5840 Borka Pezo-Nikolić, http://orcid.org/0000-0002-0504-5238•Davor Puljević, http://orcid.org/0000-0003-3603-2242

|||||||||||||||||||||||||||||||||||||||||||||||||||||||||||||||||||||||||||||||||||||||||||||||||||||||||||||||||||||||||||||||

Tachycardia is arrhythmia characterized by heart rate $>100 /$ minute. According to the width of the QRS complex it can be divided into narrow QRS ( $<120 \mathrm{~ms}$ ) and wide QRS tachycardia ( $>120 \mathrm{~ms})$. Narrow QRS tachycardia is always supraventricular which means that its source is proximal to the bundle of His, while wide QRS tachycardia can be ventricular (source is in ventricle, distal to the bundle of His) or supraventricular. The strategy of treating this two conditions is different, so correct diagnosis is prerequisite for optimal therapy.1,2 We present this case because the differential diagnosis of wide QRS tachycardia and therefore treatment planning was particularly difficult due to simultaneously present atrial fibrillation with hemodynamic instability and an acute threat to life of patient.

We present patient who was hospitalized in pulmonary edema caused by wide QRS tachycardia (Figure 1) that was resistant to standard drug therapy and demanded mechanical ventilation support. During each episode of VT, DC was done because of hemodynamic instability. Because of multi organ

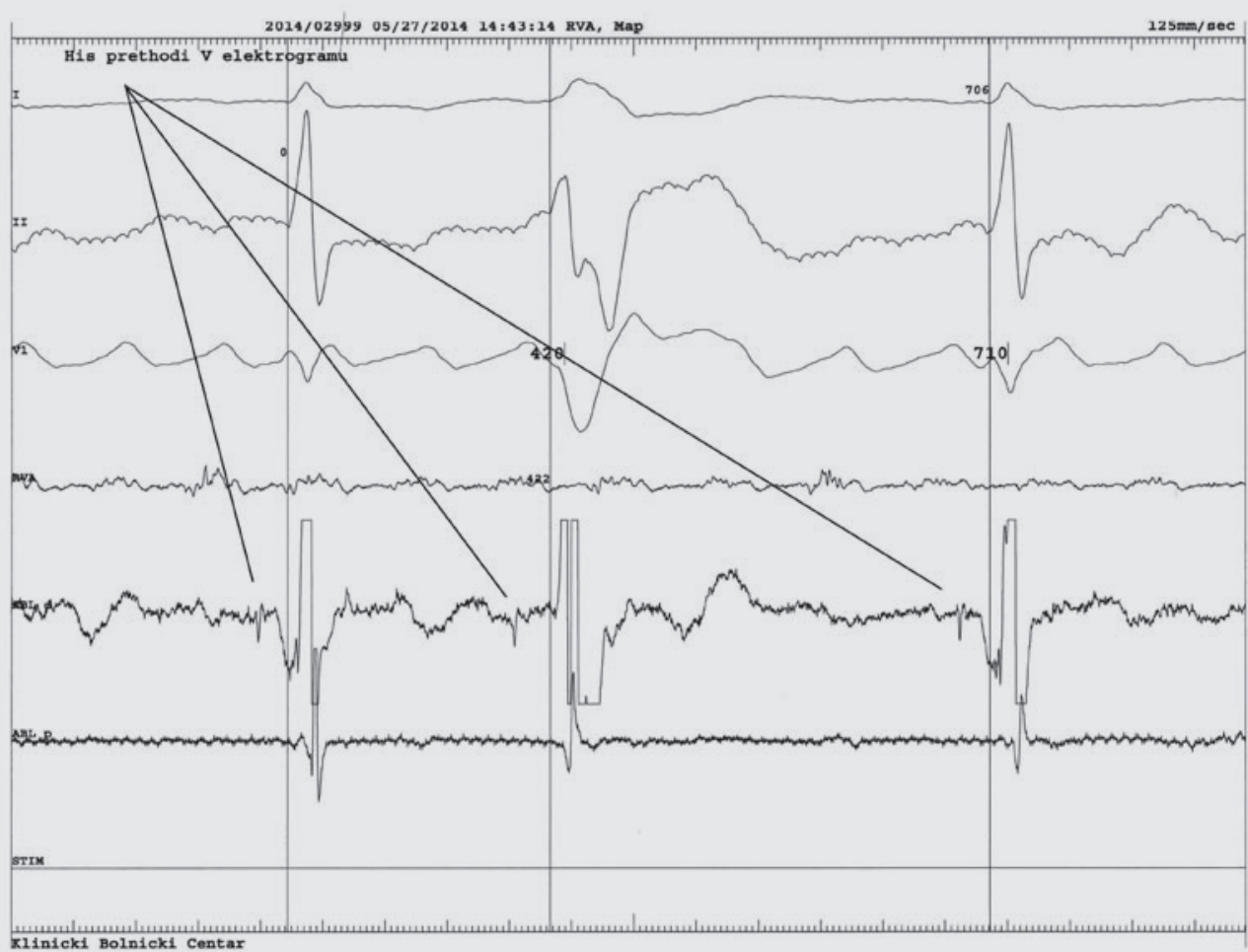

FIGURE 1. Tachycardia with wide QRS complexes. 


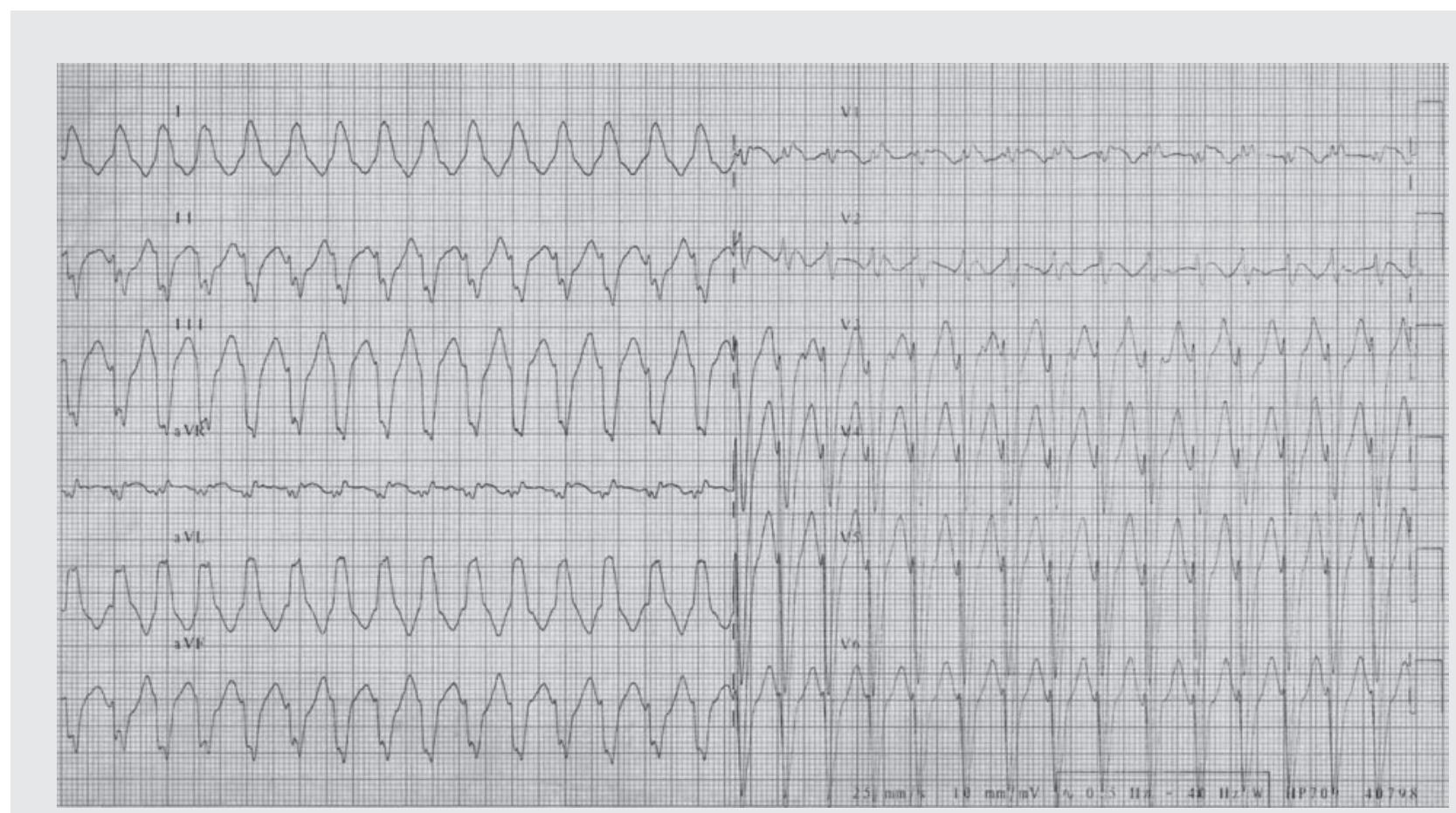

FIGURE 2. An electrophysiology study: His potential before ventricular QRS complex.

failure we considered the application of ECMO. Before ECMO urgently EPS study was done (Figure 2). Study has shown that patient has atrial flutter/fibrillation with occasionally alodromic conduction. The patient underwent successful ablation of the AV node with pacemaker implantation, with following complete recovery of the patient.

\section{LITERATURE IIIIIIIIIIIIIIIIIIIIIIIIIIIIIIIIIIIIIIIIIIIIIIIIIIIIIIIIIIIIIIIIIIIIIIIIIIIIIIIIIIIIIIIIIIIIIIIIIIIIIIIIIIIIIIIIIIIIIIIIIIIIIIIIIIII}

1. Camm AJ, Lip GY, De Caterina R, Savelieva I, Atar D, Hohnloser SH, et al; ESC Committee for Practice Guidelines (CPG). 2012 focused update of the ESC Guidelines for the management of atrial fibrillation: an update of the 2010 ESC Guidelines for the management of atrial fibrillation. Developed with the special contribution of the European Heart Rhythm Association. Eur Heart J. 2012;33(21):2719-47. DOI: http://dx.doi.org/10.1093/eurheartj/ehs253

2. Zipes DP, Camm AJ, Borggrefe M, Buxton AE, Chaitman B, Fromer M, et al; American College of Cardiology; American Heart Association Task Force; European Society of Cardiology Committee for Practice Guidelines; European Heart Rhythm Association; Heart Rhythm Society. ACC/AHA/ESC 2006 guidelines for management of patients with ventricular arrhythmias and the prevention of sudden cardiac death: a report of the American College of Cardiology/American Heart Association Task Force and the European Society of Cardiology Committee for Practice Guidelines (Writing Committee to Develop quidelines for management of patients with ventricular arrhythmias and the prevention of sudden cardiac death) developed in collaboration with the European Heart Rhythm Association and the Heart Rhythm Society. Europace. 2006;8(9):746-837. DOI: http://dx.doi.org/10.1093/europace/eul108 